\title{
AN INVESTIGATION OF ACADEMIC AND WORKPLACE DISHONESTY
}

\author{
Steven E. Mc Hugh, Sr. Centenary College, Hackettstown, NJ, USA
}

dx.doi.org/10.18374/JABE-14-1.9

\begin{abstract}
Academic and workplace dishonesty receive considerable attention in American culture. Although difficult to correlate, the suggestion of an academic and workplace dishonesty relationship has materialized. "Recent widespread corporate scandals have marred the credibility of today's business leaders - our former students causing business schools, professors, and the public to question the business school's role in these serious ethical lapses" (Beatty, 2004). To investigate this topic firsthand, a survey was conducted by this author using a convenient sample of students from a small northeastern liberal arts college. This survey provides insight into the academic and workplace dishonesty topic (Mc Hugh, Sr., 2010). This article offered the study's finding and a discussion of the relevant academic and workplace literature.
\end{abstract}

Keywords: Academic Dishonesty, Workplace Dishonesty, Business Ethics, Social Responsibility 